\title{
1 On-farm welfare monitoring of small ruminants
}

2

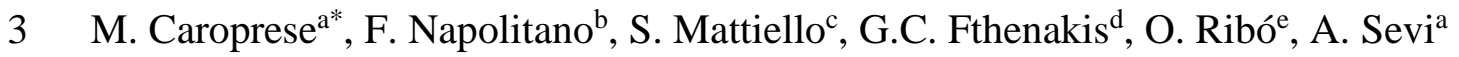

4

5

6 a Dipartimento di Scienze Agrarie, degli Alimenti e dell'Ambiente, Università di Foggia, Via 7 Napoli, 25, 71122 Foggia, Italy.

$8{ }^{b}$ Scuola di Scienze Agrarie, Forestali ed Ambientali, Università della Basilicata, Via 9 dell'Ateneo Lucano 10, 85100 Potenza, Italy.

$10{ }^{c}$ Dipartimento di Scienze Veterinarie e Sanità pubblica, Università di Milano, Via Celoria, 11 Italy.

$12{ }^{d}$ Veterinary Faculty, University of Thessaly, 43100 Karditsa, Greece

$13{ }^{e}$ FEED Unit, European Food Safety Authority (EFSA), Parma, Italy

16 * Corresponding author.

17 E-mail: mariangela.caroprese@unifg.it (Mariangela Caroprese) 


\section{ABSTRACT}

23 The paper discusses assessment of animal welfare in small ruminant production systems and 24 reports on developments regarding various monitoring schemes, which are used to assess 25 small ruminant welfare at farm level. Further, welfare assessment protocols are presented; 26 these have been derived as results in the Animal Welfare Indicators ('AWIN') project, which 27 had been funded within the European Commission's 7th Framework Program. The role of the 28 European Food Safety Authority (EFSA) in providing a scientific basis for future legislation 29 on animal welfare is described. Finally, emergency medicine to reduce small ruminant 30 suffering and support appropriate decisions to promote welfare of individual animals or 31 populations of animals is also discussed.

33 Keywords: emergency medicine, EFSA, goat, monitoring schemes, sheep, welfare indicators 34 


\section{Introduction}

40 Market demand from consumers for assurance schemes for high quality animal products (in

41 terms of health, safety and respect for animal welfare) is increasing. In response to this

42 demand, assessment of animal welfare at farm level is still an outstanding issue in the field of

43 animal husbandry. Therefore, development of on-farm welfare monitoring schemes to assess

44 welfare of farmed animals has become a need for production systems as an advisory and

45 management tool for farmers, as a tool to verify compliance with legislation or regulatory

46 standards and as a component of quality assurance schemes for consumers (Fraser, 2008).

47 Many different European Regulations have been issued regarding animal welfare. Although

48 no rules specific to small ruminants have been implemented, Commission Decision

49 2006/778/EC (European Commission, 2006) has reported that inspections of animals kept for

50 farming purposes should cover requirements laid down in specific acts, as well as general

51 animal welfare requirements as laid down in Council Directive 98/58/EC which relates to all

52 farmed species (European Commission, 1998). The animal welfare issue, however, is also

53 addressed by the European Food Safety Authority (EFSA), which is required to provide

54 scientific and technical support to Community legislation through development of scientific

55 opinions on risk factors related to all fields with direct or indirect impact on food and feed

56 safety, plant health, environment and animal health and welfare.

57 Since the beginning of the 21st Century, this topic has been widely discussed at international

58 level, in international workshops (e.g., Sørensen and Sandøe, 2001; Webster and Main, 2003)

59 and in specific working groups, e.g., the European Action 846 of the COST Framework

60 'Measuring and monitoring farm animal welfare' (Blokhuis et al., 2003). That COST action

61 had led to the Welfare Quality ${ }^{\circledR}$ EU project, which had been funded by the European

62 Commission in 2004 with the aim to developing on-farm welfare monitoring schemes. The

63 project involved 43 establishments (from 13 European and four Latin American countries)

64 and resulted in the publication of welfare assessment protocols for cattle, pigs and poultry;

65 however, the development of on-farm welfare assessment protocols for small ruminants was

66 not addressed. In 2011, the EU's 7th Framework Program for Research (FP7) funded the

67 'AWIN' (Animal Welfare Indicators) project, which aimed at improving animal welfare by 
68 developing, integrating and disseminating information regarding animal welfare indicators in

69 animal species that had not been previously covered in the Welfare Quality ${ }^{\circledR}$ project,

70 including small ruminants.

71 Development of awareness and of regulations regarding farm animal welfare follows closely 72 changes in under- and post-graduate teaching in the field in tertiary education. However, often 73 animal welfare teaching is not associated with clinical skills and diagnostic or monitoring 74 procedures in farms do not always take into account welfare considerations of individuals or 75 populations under consideration (Illmann et al., 2014).

76 In order to develop effective welfare assessment schemes, the role of the scientific community 77 should be enhanced through the involvement of the relevant stakeholders, e.g., producer 78 associations, animal breeding organisations, retailer and consumer organisations, policy 79 makers and veterinarians. In particular, veterinarians are required to evaluate, in cases of 80 small ruminant emergency, which remedial options for sick animals or for animals at risk of 81 becoming_sick promote their welfare status. The present review discusses welfare assessment 82 from various perspectives applied to small ruminants.

\section{2. Monitoring schemes}

87 According to Scott et al. (2001), monitoring schemes should include indicators that are valid, 88 reliable and sensitive. In addition, they should be practically feasible to apply in the field. 89 Two broad categories of indicators can be used to assess animal welfare at farm level (Main et 90 al., 2003): (i) animal-based welfare measures (e.g., behavioural measurements, productivity, 91 health issues) and (ii) resource-based influencing factors (e.g., stocking density, feeding 92 regime, milking procedures).

93 Animal welfare monitoring schemes are generally based on the assessment of negative 94 consequences of farming factors on animals, while there are only few examples of positive 95 aspects being evaluated (e.g., the positive terms of qualitative behaviour assessment in the 96 AWIN and Welfare Quality ${ }^{\circledR}$ protocols). However, possible links between these adverse 97 effects on animal welfare and risk factors (e.g., poor flooring as risk factor for lameness) have 98 seldom been investigated. Therefore, albeit valid and reliable, such schemes can only be used 
to express a scientifically-based judgement on the welfare state of the animals, whereas little

100 is done to promote a continuous process of animal welfare improvement (Whay, 2008).

101 Sheep welfare has been investigated in a number of studies, in which the effect of 102 management stressors has been assessed. Conversely, on-farm monitoring schemes for 103 assessing the welfare of small ruminants had not been available until a few years ago. 104 Napolitano et al. (2009) have adapted a protocol scientifically validated for cattle, termed 105 'Animal Needs Index (ANI) 35 L 2000' (Bartussek et al., 2000), for the welfare evaluation of 106 sheep. The protocol used resource measures, which included structural and technical elements 107 (e.g., space allowance, feeding facilities) and showed to be feasible (mean time required to 108 perform welfare assessment was 85 min. per farm, with no sophisticated equipment necessary 109 in both time-consuming and financial terms) and reliable (inter-observer reliability of the 110 scores was high). As the ANI was a system mainly based on resource variables, several 111 animal-based variables were tested for possible inclusion in the protocol. Avoidance distance 112 showed high levels of convergent and scientific validity and intra-observer reliability (defined 113 by Waiblinger et al., 2006). Lameness, integument alterations and body condition score were 114 not tested for validity, but showed excellent intra-observer reliability (Napolitano et al., 115 2011), whereas good inter-observer reliability was noted for integument alteration, hoof 116 overgrowth, lameness and dirtiness (Napolitano et al., 2009). Subsequently, monitoring 117 systems with animal-based measures, dealing with behaviour, health and physiology of the 118 animals or a combination of resource- or animal-based measures, have been developed to 119 obtain a valid assessment of animal welfare (Welfare Quality ${ }^{\circledR}$ project).

120 The main objective of the AWIN was the development of animal welfare indicators in sheep, 121 goats, horses, donkeys and turkeys. The overall research objectives were pursued through four 122 work-packages (WP1: development of animal welfare protocols; WP2: study of the impact of 123 pain and disease on animal welfare; WP3: study of the effects of pre-natal factors on 124 development and welfare of the offspring; and WP4: promotion of research and education in 125 animal welfare). These objectives focused on species that, although commercially relevant 126 worldwide, had been overlooked in previous animal welfare assessments. Both for sheep and 127 goats, the AWIN protocols were developed following a four-stage process: stage 1 included 128 literature review (Battini et al., 2014a) and expert panel meetings to select the most promising 129 candidate indicators for inclusion into the protocols, stage 2 included tests of selected 
130 indicators for validity, reliability and feasibility, stage 3 included development and testing of

131 prototype protocols in commercial farms in various European countries and stage 4 included

132 refinement of the prototypes, taking into account the outcome of the tests and advice from

133 stakeholders. Stakeholders were involved during all these stages, through participation in

134 conference meetings and participation to direct or on-line surveys, in order to increase the

135 acceptability of the final protocols (Battini et al., 2014b).

136 AWIN welfare assessment protocols for sheep and goats used a two-level approach; the first

137 level welfare assessment protocol consisted of a quick screening of the flock, including a

138 selection of robust and feasible animal-based indicators collected with no or minimal animal

139 handling. Depending on the outcome of the first level assessment, a second level, which

140 consisted of a more comprehensive and an in-depth assessment requiring restraint of the

141 animals and collection of individual data, was recommended. That approach was chosen, in

142 order to increase the feasibility of the assessment.

143 For both species, selection of the indicators was based on the four principles and twelve

144 criteria defined by the Welfare Quality ${ }^{\circledR}$ project, which covered all aspects of animal welfare.

145 Animal-based indicators were selected whenever possible; when no valid, reliable and

146 feasible animal-based indicators were available to cover welfare criteria, resource-based

147 indicators were used.

148 For sheep, the animal-based measures taken at the first level were: qualitative behaviour 149 assessment, quantitative behaviour assessment (e.g., social withdrawal, panting, stereotypy, 150 and excessive itching), fearfulness assessed using human approach (minimum distance, flight 151 distance, time to resume normal behaviour), physical assessment of fleece (cleanliness, 152 quality), tail length (full, docked well, docked short) and lameness, whereas the environment 153 was assessed outdoors (in terms of water supply, shelter provision, landscape) and indoors (in 154 terms of water supply and stocking density). In addition, lamb mortality was recorded. At the 155 second level, the following aspects were evaluated: gingival and eye mucosa (colour), eyes 156 (e.g., presence of ocular discharge), body and head lesions, respiratory quality (e.g., 157 coughing), fleece quality (e.g., fleece loss), coat (cleanliness), legs (e.g., injuries), body158 condition scoring (as described by Russell et al., 1969), udder lesions and mastitis, tail 159 (length), faecal soiling (on a 5-point scale), lameness (on a 4-point scale) and overgrown hoof 
160 (AWIN, 2015a;b). Details of welfare assessment indicators for first and second level 161 assessment are described in Table 1 (sheep) or Table 2 (goats).

162 An innovative aspect of the AWIN protocols was the presentation of the outcome to farmers.

163 First, in contrast to previous welfare schemes, the AWIN project decided to provide positive

164 feedback to farmers by presenting the results of the assessment in terms of animals that did 165 not present welfare problems. Further, the AWIN project aimed at giving results that could be 166 of help to farmers to improve the welfare level, therefore the outcome was informative about 167 the main welfare problems on the farm and did not produce an overall assessment score as in 168 the Welfare Quality ${ }^{\circledR}$ project. For these reasons, the outcome consisted of a visual output that 169 highlighted positive conditions and plotted the farm situation against that of a reference 170 population, giving the possibility to the farmer to compare the welfare level of a farm with 171 that of other farms and to immediately understand which were the strengths and weaknesses 172 from a welfare point of view. This was aimed at promoting identification of best practices and 173 implementation for welfare management and continuous improvement.

175 3. The European Union strategy on animal welfare: the role of European Food Safety 176 Authority

178 Another approach in the development of tools for on-farm control and management of animal 179 welfare was the use of the risk assessment (RA) methodology, which allowed identification of 180 the major hazards that posed potential risks to animal welfare. This approach started with the 181 identification of the hazards, the quantification of their likelihoods and the potential impacts 182 in terms of intensity, duration and prevalence in order to rank the risks and prioritize areas of 183 intervention where monitoring and managing of animal welfare risks may be needed (Ribó 184 and Serratosa, 2009). The European Food Safety Authority (EFSA) can be asked by the 185 various European Commission services, as well as also by the European Parliament, EU 186 Members States or itself ('self-mandate'), to provide a scientific assessment following, 187 whenever possible, a RA approach. EFSA has developed RA methodologies for a number of 188 farm animal species and production systems (e.g. dairy cattle, beef cattle, pig, chicken, fish). 189 Risk assessment has been defined by the EFSA Panel on Animal Health and Welfare as a 190 scientifically-based process consisting of exposure assessment (in terms of level, duration, 
191 frequency and variability of exposure to hazards), consequence characterisation (i.e., 192 evaluation of the nature of animal welfare effects caused by a hazard) and risk 193 characterisation (estimation, including associated uncertainties, of the probability of 194 occurrence and magnitude of adverse animal welfare effects) (EFSA Panel on Animal Health 195 and Welfare, 2012d). Risk assessment is part, along with risk management and risk 196 communication, of a wider process termed 'risk analysis'. The EFSA Panel on Animal Health 197 and Welfare is composed by 21 independent scientific experts. Of these, approximately one 198 third consists of experts in animal welfare issues, one third of experts in animal diseases and 199 one third of experts in animal health and welfare horizontal issues related to risk assessment 200 methodologies, epidemiology and modelling. The panel is responsible for all adopted 201 scientific opinions and receives the full administrative support by EFSA staff. When EFSA 202 receives a request to provide scientific advice, a working group is set up. The working group 203 is composed of experts on the specific issue and a risk assessor in charge of defining the risk 204 pathways and the risk assessment methodology. Through different meetings, the working 205 group collects all available scientific data and information on the issue, performs the risk 206 assessment when pertinent and possible and drafts conclusions and recommendations. The 207 process results in a draft scientific opinion, sometimes opened for public consultation, which 208 is finally discussed, reviewed and adopted by the experts' panel. In agreement with EFSA's 209 policy on transparency, all scientific documents are published in the EFSA's website 210 (www.efsa.europa.eu).

211 In particular, EFSA Panel on Animal Health and Welfare provides specific advice on risk 212 factors related to animal diseases and welfare, mainly of food producing animals, including 213 fish. The outcomes of the risk assessment methodology together with the identification of 214 welfare indicators will allow the establishment and implementation of welfare control and 215 monitoring plans at farm level and detection of poor welfare situations. Future legislative 216 provisions based on appropriate scientific evidence should include animal-based welfare 217 indicators or assessment systems, which will support decision making on the acceptable 218 conditions for farmed animals and will be used to underpin control and monitoring of animal 219 welfare at farm level (Ribó and Serratosa, 2009).

220 During the period 2003 to 2013, the EFSA Panel on Animal Health and Welfare delivered 221109 scientific opinions regarding various animal diseases $(n=60)$ or welfare $(n=49)$ matters. 
222 Other EFSA panels and units have also been involved in the delivery of opinions related to 223 animal health and welfare (i.e., biological hazards, feed additives, contaminants, zoonoses).

224 The main objective of the scientific opinions on animal welfare is the identification of hazards 225 leading to negative welfare outcomes and make recommendations to reduce or eliminate these 226 hazards. In 2006, EFSA was asked by the European Commission to include measurable 227 welfare indicators, whenever possible, in the conclusions and recommendations of the future 228 scientific opinions on animal welfare. In 2011, EFSA was further asked to identify how 229 animal-based measures could be used to ensure fulfilment of the recommendations of the 230 EFSA scientific opinions on animal welfare and how the assessment protocols suggested by 231 the Welfare Quality ${ }^{\circledR}$ project covered the main hazards identified in EFSA scientific opinions 232 and vice-versa. The Welfare Quality ${ }^{\circledR}$ protocols use animal-based measures to assess animal 233 welfare by measuring the magnitude of the welfare outcomes. Therefore, the results of the 234 welfare assessments would be used to take appropriate measures to improve welfare. These 235 results will also provide crucial quantitative data to be used in future animal welfare risk 236 assessments to identify additional welfare hazards. Consequently, the identification of welfare 237 hazards in the scientific opinions will support further development of animal-based indicators 238 for welfare assessment at farm level (Ribó and Blokhuis, 2012). Following this approach, in 239 2012, three scientific opinions regarding use of animal-based measures to assess welfare of 240 pigs, cows and broilers were published (EFSA Panel on Animal Health and Welfare, $2412012 \mathrm{a} ; \mathrm{b} ; \mathrm{c})$. The three opinions commonly concluded that the Welfare Quality ${ }^{\circledR}$ protocols 242 covered most of the hazards identified in the EFSA's scientific opinion and that animal-based 243 measures were necessary to assess whether the recommendations for welfare improvement 244 have been achieved. The work continued to cover all farm species. A scientific opinion on 245 risk assessment for animal welfare (EFSA Panel on Animal Health and Welfare, 2012d) and a 246 statement on the use of animal-based measures to assess animal welfare (EFSA Panel on 247 Animal Health and Welfare, 2012e), establishing a common framework for future scientific 248 opinions, were also published in 2012.

249 In December 2014, the EFSA Panel of Animal Health and Welfare adopted a scientific 250 opinion on the welfare risks related to the farming of sheep for wool, meat or milk production 251 (EFSA Panel on Animal Health and Welfare, 2014). In the same way as for the Welfare 252 Quality $^{\circledR}$ project, the welfare protocols developed in the AWIN project (AWIN, 2015a;b) 
253 were used in this opinion as a basis to identify animal-based welfare measures in small

254 ruminants. In this case, the working group on sheep welfare adopted a novel approach starting

255 with the description of the main categories of management systems: shepherding (continuous

256 presence of the shepherd with the flock), intensive (no outdoor access), semi-intensive

257 (housing during the night and part of the day), semi-extensive (kept in fenced pasture and 258 receiving feeding supplementation), extensive (no fencing but receiving feeding 259 supplementation), very-extensive (no fencing and receiving no supplementation) or mixed 260 system. Subsequently, in agreement with Phythian et al. (2011), a bottom-up approach had 261 been followed with the identification of the main welfare adverse effects of farming as 262 resulted from the analysis of a questionnaire circulated among over 300 sheep farming 263 experts, including academics, practitioners or farmers. Overall, the main issues that were 264 considered to adversely affect welfare of sheep were (i) for ewes: lameness, thermal 265 discomfort, enteric disorders, mastitis and skin disorders and (ii) for lambs: pain induced by 266 management procedures (e.g., castration), enteric disorders, thermal discomfort and mis267 mothering. A restricted group of experts was then asked to associate the main risk factors to 268 those adverse effects following the scheme reported in Table 3 (for the sake of brevity, only 269 consequences for ewes are shown as an example). The identification of adverse effects and 270 related risk factors was conducted within the framework set by the Welfare Quality ${ }^{\circledR}$ protocol, 271 consisting of 4 welfare principles and 12 welfare criteria. The pitfall of the risk assessment 272 approach is that it is not usually performed on individual farms, therefore it can be used as a 273 tool to support scientifically driven policy making, while identifying and characterising risk 274 factors potentially threatening sheep welfare. However, no indications regarding specific farm 275 situations may be given in terms of animal welfare or as a tool for continuous welfare 276 improvement.

278 4. Welfare considerations in small ruminant emergency medicine

280 In small ruminants, extensive and very extensive rearing systems are practiced frequently. 281 These systems are often accompanied by lack of monitoring veterinarian programs. Hence, 282 emergency medicine plays a key role in providing rapid and effective veterinary and nursing 283 care in cases threatening the life of small ruminants and/or their health and production. 
284 Further, in emergency medicine in small ruminant health management, financial constraints,

285 as well as the welfare of sick or at risk to become sick animals, should always be taken into 286 account.

287 Emergency medicine in individuals aims at treating disease problems with an immediate risk

288 for the life of animals. These can refer to problems in young (e.g., neonatal hypothermia) or 289 adult (e.g., dystocia, urethral obstruction) animals and can be dealt with by using knowledge 290 from various veterinary specialities (e.g., anaesthesiology, obstetrics, neurology, surgery).

291 Emergency medicine in populations aims to control various diseases with a risk to the animals 292 of a farm or a geographical region. Moreover, it functions as a safety net for animal 293 production. These diseases may be of endemic (e.g., cases of abortion), epidemic (e.g., 294 bluetongue disease in Northern Europe) or emerging (e.g., Schmallenberg disease) nature and 295 can be dealt with by using knowledge from various scientific fields (e.g., diagnostic medicine, 296 epidemiology, preventive medicine) (Arsenos and Fthenakis, 2014).

297 In all circumstances, the welfare status of individuals must be maintained to a standard 298 appropriate for those individuals at that moment. The traditional 'cost-benefit' analysis will 299 need to be extended to take into account facets beyond the traditional financial implications, 300 to a meaning that includes the degree of suffering acceptable by the affected animals, as well 301 as taking into account that positive outcomes of treatment are by no means certain (Roger, 302 2014).

303 The peri-parturient period is a time in the life of a ewe or doe when most emergency problems 304 would arise. This is mainly the effect of pressure in the metabolism of the pregnant animal 305 and the specific financial circumstances at that stage. Pregnancy toxaemia, abortion, dystocia 306 and hypocalcaemia (among others) require an immediate action from a veterinarian. 307 Nevertheless, there are circumstances, in which the scientific literature indicates an 308 unfavourable prognosis. For example, in pregnancy toxaemia, these include the development 309 of neurological signs in the ewe and the in utero death of foetus(es) (Brozos et al., 2011). 310 Therapeutic efforts need to take place for a long period and can often be unsuccessful; at the 311 same time, veterinary expenses can be high, but unrewarding to the farmer. Moreover, in such 312 cases, welfare status of the affected animal is reduced and, possibly, may never be restored. 313 The attending veterinarian will need to take a professional decision, based on their scientific 
314 background: is effective treatment a feasible option or is euthanasia the best approach for the

315 welfare of the affected animal?

316 The first days of life of a sheep/goat will be the most stressful period in the life of that animal.

317 A variety of adverse conditions, often caused or predisposed by inappropriate management

318 (e.g., liver rupture, hypothermia, dislocation) can affect newborns, reducing their welfare

319 status and requiring immediate veterinary care (Fragkou et al., 2010). Again, some of these

320 disorders, depending on the severity of each condition, may have an adverse prognosis, which

321 will require from the attending veterinarian a welfare evaluation. Moreover, in those

322 scenarios, diseased animals have a small financial value and, further, have not produced any

323 economic benefits to the farmer. The attending veterinarian will need to make a professional

324 decision, based on its scientific and professional knowledge: is the treatment an option that

325 would financially compensate the farmer in the future or is euthanasia the preferred approach

326 for financial viability of the farm?

327 There are many examples of emergency medicine in animal populations (e.g. foot-and-mouth

328 disease, sheep pox), in which healthy individuals, with generally acceptable standards of

329 welfare, are accounted for euthanasia. This occurs within the appropriately defined

330 surveillance areas. The attending veterinarian will need to make a professional decision, based

331 on their scientific background: is euthanasia of the defined cohort a means to control the

332 disease or, possibly, euthanasia of a much larger number of animals would be required in the

333 future?

334 In all cases, accurate and rapid diagnosis of the problem is paramount. This should be 335 followed by analysis of the situation and evaluation of the various remedial options. 336 Assessment of the welfare status of the animals, coupled with prognosis of the probabilities 337 for recovery, as well as the time-scale for achieving full recovery needs to be an integral 338 element of the decision process. That way, emergency responses are correct and promote 339 welfare status of individual animals or populations of animals.

$341 \quad$ 5. Concluding remarks

343 The development of on-farm welfare assessment protocols is of great practical importance. 344 Within the EU's 7th Framework Program for Research (FP7), the AWIN project had as a 
345 main objective to promote the identification of best practices and their implementation for

346 welfare management and improvement. The development of on-farm welfare monitoring

347 protocols can contribute to markedly improve the quality standards on the management of

348 small ruminants. Moreover, most of sheep and goat products are officially recognized in the

349 European Union legislation with a protected designation, hence inclusion of a welfare

350 monitoring system into the specifications of such products would further improve their market

351 value. Within the general aim to promote the welfare of small ruminants, EFSA plays a

352 central role in providing scientific basis for future legislation. In addition, emergency

353 medicine is fundamental to minimize suffering and support appropriate decisions concerning

354 medical treatments and euthanasia.

355 Further reports are needed about concerns and feelings of shepherds and goatherds with

356 respect to welfare issues in their production systems. The delivering of the best practices

357 identified and promoted within AWIN project and EFSA scientific advice could implement

358 the diffusion of welfare management of small ruminants with the contribution of animal

359 welfare experts.

360 Conflict of interest statement

361 None of the authors of this paper has a financial or personal relationship with other people or

362 organizations that could inappropriately influence or bias the content of the paper.

363

364

365 
Arsenos, G.I., Fthenakis, G.C., 2014. Control of emergency cases within small ruminant populations. Proceedings of the 3rd Greek Conference for Farm Animal Medicine and Food Hygiene (Ioannina, Greece) p. 38.

AWIN, 2015a. AWIN Welfare Assessment Protocol for Sheep. doi: 10.13130/AWIN_sheep_2015.

AWIN, 2015b. AWIN Welfare Assessment Protocol for Goats. doi: 10.13130/AWIN_goats_2015.

Bartussek, H., Leeb, C.H., Held. S., 2000. Animal Needs Index for Cattle ANI 35 L/2000. Federal Research Institute for Agriculture in Alpine Regions BAL Gumpenstein, Irdning, Austria.

Battini, M., Barbieri, S., Ferrari, L., Bruni, G., Zanatta, G., Canali, E., Mattiello S., 2014a. Un protocollo per la valutazione del benessere nella capra: risultati della consultazione con le Parti Sociali in Italia. Large Anim. Rev. 4 (Suppl. 1), 114.

Battini, M., Vieira, A., Barbieri, S., Ajuda, I., Stilwell, G., Mattiello, S., 2014b. Animal-based indicators for on-farm welfare assessment for dairy goats. J. Dairy Sci. 97, 6625-6648.

Blokhuis, H.J., Jones, R.B., Geers, R., Miele, M., Veissier, I., 2003. Measuring and monitoring animal welfare: transparency in the food product quality chain. Anim. Welfare $12,445-455$.

Brozos, C., Mavrogianni, V.S., Fthenakis, G.C., 2011. Treatment and control of periparturient metabolic diseases: pregnancy toxaemia, hypocalcemia, hypomagnesemia. Vet. Clin. N. Am.-Food A. 27, 105-113.

European Commission, 1998. Council Directive 98/58/EC concerning the protection of animals kept for farming purposes. Official Journal of the European Union L 221, 23-27.

European Commission, 2006. Decision concerning minimum requirements for the collection of information during the inspections of production sites on which certain animals are kept for farming purposes (2006/778/CE). Official Journal of the European Union L 314, 39-47.

EFSA Panel on Animal Health and Welfare, 2012a. Scientific opinion on the use of animalbased measures to assess welfare of dairy cows. EFSA Journal 10, 2554.

EFSA Panel on Animal Health and Welfare, 2012b. Scientific opinion on the use of animalbased measures to assess welfare in pigs. EFSA Journal 10, 2512.

EFSA Panel on Animal Health and Welfare, 2012c. Scientific opinion on the use of animalbased measures to assess welfare of broilers. EFSA Journal 10, 2774.

EFSA Panel on Animal Health and Welfare, 2012d. Guidance on risk assessment for animal welfare. EFSA Journal 10, 2513.

EFSA Panel on Animal Health and Welfare, 2012e. Statement on the use of animal-based measures to assess the welfare of animals. EFSA Journal 10, 2767. 
405

406

407

408

409

410

411

412

413

414

415

416

417

418

419

420

421

422

423

424

425

426

427

428

429

430

431

432

433

434

435

436

437

438

439

440

441

442

443

444

EFSA Panel on Animal Health and Welfare, 2014. Scientific Opinion on the welfare risks related to the farming of sheep for wool, meat and milk production. EFSA Journal 12, 3933.

Fragkou, I.A., Mavrogianni V.S., Fthenakis, G.C., 2010. Diagnostic investigation of deaths of newborn lambs. Small Rumin. Res. 92, 41-44.

Fraser, F., 2008. Understanding Animal Welfare: The Science in its Cultural Context. WileyBlackwell, Oxford.

Illmann, G., Keeling, L., Melišova, M., Šimečkova, M., Ilieski, V., Winckler, C., Košt’al, L., Meunier-Salaun, M.C., Mihina, S., Spoolders, H., Fthenakis, G, Šarova, R., Spinka, M., 2010. Mapping farm animal welfare education at university level in Europe. Anim. Welfare 23, 401-410.

Main, D.C.J., Kent, J.P., Wemelsfelder, F., Ofner, E., Tuyttens F.A.M., 2003. Applications for methods of on-farm welfare assessment. Anim. Welfare 12, 523-528.

Napolitano, F., De Rosa, G., Ferrante, V., Grasso, F., Brughieri, A., 2009. Monitoring the welfare of sheep in organic and conventional farms using an ANI 35 L derived method. Small Rumin. Res. 83, 49- 57.

Napolitano F., De Rosa G., Girolami A., Scavone M., Braghieri A., 2011. Avoidance distance in sheep: test-retest reliability and relationship with stockman attitude. Small Rumin. Res. 99, 81-86.

Phythian, C.J., Michalopoulou, E., Jones, P.H., Winter, C.J., Clarkson, M.J., Stubbings, L.A., Grove-White, D., Cripps, P.J., Duncan, J.S., 2011. Validating indicators of sheep welfare through a consensus of expert opinion. Animal 5, 943-952.

Ribó, O., Blokhuis, H., 2012. Risk assessment methodology and identification of animalbased indicators to assess animal welfare at farm level. In: Jakobsson C. (ed.). Ecosystem Health and Sustainable Agriculture, vol. 1, Sustainable Agriculture. Baltic University Programme, Uppsala, pp. 362-368.

Ribó, O., Serratosa, J., 2009. History and procedural aspects of the animal welfare risk assessment at EFSA. In: Smulders, F.J.M, Algers, B. (eds). Food Safety Assurance and Veterinary Public Health, vol. 5, Welfare of Production Animals: Assessment and Management of Risks. Wageningen Academic Publishers, Wageningen, pp. 307-337.

Roger, P.A., 2014. Ethical concepts and dilemmas for emergency medicine in small ruminants. Proceedings of the 3rd Greek Conference for Farm Animal Medicine and Food Hygiene (Ioannina, Greece) pp. 36-37.

Russel, A.J.F., Doney, J.M., Gunn, R.G., 1969. Subjective assessment of body fat in live sheep. J. Agr. Sci. 72, 451-454.

Scott, E.M., Nolan, A.M., Fitzpatrick, J.L., 2001. Conceptual and methodological issues related to welfare assessment: a framework for measurement. Acta Agricoltura Scandinavica A Suppl. 30, 5-10.

Sørensen, J.T., Sandøe, P., 2001. Assessment of animal welfare at farm or group level. Acta Agricoltura Scandinavica A Suppl. 30. 
445 Waiblinger, S., Boivin, X., Pedersen, V., Tosi, M.V., Janczak, A.M., Visser, E.K., Jones, 446 R.B., 2006. Assessing the human-animal relationship in farmed species: a critical review. 447 Appl. Anim. Behav. Sci. 101, 185-242.

448 Webster, A.J.F., Main, D.C.J., 2003. Proceedings of the 2nd International Workshop on the 449 Assessment of Animal Welfare at Farm and Group Level (Bristol, United Kingdom). $450 \quad$ Anim. Welfare vol. 12, issue 4.

451 Whay, H. R., 2008. On-farm animal welfare assessments and audits in the UK. Proceedings of 452 the 41st Annual Conference of the American Association of Bovine Practitioners 453 454 455 456 457 458 459 460 461 462 463 
465 Table 1. Animal welfare indicators of the AWIN welfare assessment protocol for sheep,

466 divided according to principles and criteria (first or second level welfare assessment) (AWIN, 467 2015a).

\begin{tabular}{|c|c|c|c|}
\hline \multirow{2}{*}{$\begin{array}{l}\text { Welfare } \\
\text { principles }\end{array}$} & \multirow{2}{*}{ Welfare criteria } & \multicolumn{2}{|l|}{ Welfare indicators } \\
\hline & & First level & Second level \\
\hline \multirow{2}{*}{$\begin{array}{l}\text { Good } \\
\text { feeding }\end{array}$} & Appropriate nutrition & Lamb mortality & Body condition score \\
\hline & $\begin{array}{l}\text { Absence of prolonged } \\
\text { thirst }\end{array}$ & Water availability & \\
\hline \multirow{3}{*}{$\begin{array}{l}\text { Good } \\
\text { housing }\end{array}$} & Comfort around resting & Fleece cleanliness & Fleece cleanliness \\
\hline & Thermal comfort & $\begin{array}{l}\text { Panting, access to } \\
\text { shade/shelter (only } \\
\text { animals living outdoors) }\end{array}$ & \\
\hline & Ease of movement & $\begin{array}{l}\text { Stocking density (only } \\
\text { housed animals) }\end{array}$ & $\begin{array}{l}\text { Hoof overgrowth (only } \\
\text { housed animals) }\end{array}$ \\
\hline \multirow{3}{*}{$\begin{array}{l}\text { Good } \\
\text { health }\end{array}$} & Absence of injuries & & $\begin{array}{l}\text { Body and head lesions, leg } \\
\text { injuries }\end{array}$ \\
\hline & Absence of disease & $\begin{array}{l}\text { Lameness; faecal soiling; } \\
\text { fleece quality }\end{array}$ & $\begin{array}{l}\text { Lameness, faecal soiling, } \\
\text { mucosa colour, ocular } \\
\text { discharge, mastitis and } \\
\text { udder lesions (lactating } \\
\text { ewes only), respiratory } \\
\text { quality, fleece quality }\end{array}$ \\
\hline & $\begin{array}{l}\text { Absence of pain and } \\
\text { pain induced by } \\
\text { management } \\
\text { procedures }\end{array}$ & Tail length & Tail length \\
\hline \multirow{3}{*}{$\begin{array}{l}\text { Appropriat } \\
\text { e } \\
\text { behaviour }\end{array}$} & $\begin{array}{l}\text { Expression of social } \\
\text { behaviour }\end{array}$ & Social withdrawal & \\
\hline & $\begin{array}{l}\text { Expression of other } \\
\text { behaviours }\end{array}$ & $\begin{array}{l}\text { Stereotypy; excessive } \\
\text { itching }\end{array}$ & \\
\hline & $\begin{array}{l}\text { Good human-animal } \\
\text { relationship }\end{array}$ & Familiar human approach & \\
\hline
\end{tabular}


474 Table 2. Animal welfare indicators of the AWIN welfare assessment protocol for goats, 475 divided according to principles and criteria (first or second level welfare assessment) (AWIN, 476 2015b).

\begin{tabular}{|c|c|c|c|}
\hline \multirow{2}{*}{$\begin{array}{l}\text { Welfare } \\
\text { principles }\end{array}$} & \multirow{2}{*}{ Welfare criteria } & \multicolumn{2}{|l|}{ Welfare indicators } \\
\hline & & First level & Second level \\
\hline \multirow{2}{*}{$\begin{array}{l}\text { Good } \\
\text { feeding }\end{array}$} & Appropriate nutrition & $\begin{array}{l}\text { Hair coat condition, } \\
\text { queuing at feeding }\end{array}$ & $\begin{array}{l}\text { Body condition score, hair } \\
\text { coat condition, queuing at } \\
\text { feeding }\end{array}$ \\
\hline & $\begin{array}{l}\text { Absence of prolonged } \\
\text { thirst }\end{array}$ & Queuing at drinking & Queuing at drinking \\
\hline \multirow{3}{*}{$\begin{array}{l}\text { Good } \\
\text { housing }\end{array}$} & $\begin{array}{l}\text { Comfort around } \\
\text { resting }\end{array}$ & Bedding & Bedding \\
\hline & Thermal comfort & Thermal stress & Thermal stress \\
\hline & Ease of movement & $\begin{array}{l}\text { Kneeling at the feeding } \\
\text { rack }\end{array}$ & $\begin{array}{l}\text { Kneeling at the feeding } \\
\text { rack }\end{array}$ \\
\hline \multirow{3}{*}{$\begin{array}{l}\text { Good } \\
\text { health }\end{array}$} & Absence of injuries & Severe lameness & Severe lameness \\
\hline & Absence of disease & $\begin{array}{l}\text { Abscesses, hair coat } \\
\text { condition, oblivion, } \\
\text { overgrown claws, udder } \\
\text { asymmetry }\end{array}$ & $\begin{array}{l}\text { Abscesses, body condition } \\
\text { score, faecal soiling, hair } \\
\text { coat condition, nasal } \\
\text { discharge, oblivion, ocular } \\
\text { discharge, overgrown } \\
\text { claws, udder asymmetry }\end{array}$ \\
\hline & $\begin{array}{l}\text { Absence of pain and } \\
\text { pain induced by } \\
\text { management } \\
\text { procedures }\end{array}$ & $\begin{array}{l}\text { Improper disbudding, } \\
\text { severe lameness }\end{array}$ & $\begin{array}{l}\text { Improper disbudding, } \\
\text { severe lameness }\end{array}$ \\
\hline \multirow{4}{*}{$\begin{array}{l}\text { Appropriat } \\
\text { e } \\
\text { behaviour }\end{array}$} & $\begin{array}{l}\text { Expression of social } \\
\text { behaviour }\end{array}$ & $\begin{array}{l}\text { Queuing at drinking, } \\
\text { queuing at feeding }\end{array}$ & $\begin{array}{l}\text { Queuing at drinking, } \\
\text { queuing at feeding }\end{array}$ \\
\hline & $\begin{array}{l}\text { Expression of other } \\
\text { behaviours }\end{array}$ & Oblivion & Oblivion \\
\hline & $\begin{array}{l}\text { Good human-animal } \\
\text { relationship }\end{array}$ & $\begin{array}{l}\text { Latency to the first contact } \\
\text { test }\end{array}$ & $\begin{array}{l}\text { Latency to the first contact } \\
\text { test }\end{array}$ \\
\hline & $\begin{array}{l}\text { Positive emotional } \\
\text { state }\end{array}$ & $\begin{array}{l}\text { Qualitative behaviour } \\
\text { assessment }\end{array}$ & $\begin{array}{l}\text { Qualitative behaviour } \\
\text { assessment }\end{array}$ \\
\hline
\end{tabular}


482 Table 3. Example of association between the main welfare consequences identified in sheep 483 and the corresponding risk factors (hazards) in the main management systems.

\begin{tabular}{|c|c|c|c|c|}
\hline \multirow{2}{*}{$\begin{array}{l}\text { Welfare } \\
\text { consequenc } \\
\text { e }\end{array}$} & \multicolumn{4}{|c|}{ Management system } \\
\hline & Shepherding & Intensive & Semi-intensive & Extensive \\
\hline $\begin{array}{l}\text { Prolonged } \\
\text { hunger }\end{array}$ & $\begin{array}{l}\text { Poor pasture } \\
\text { quality, lack of } \\
\text { supplementation }\end{array}$ & & & $\begin{array}{l}\text { Poor pasture } \\
\text { quality, lack of } \\
\text { supplementation }\end{array}$ \\
\hline $\begin{array}{l}\text { Thermal } \\
\text { stress }\end{array}$ & $\begin{array}{l}\text { Lack of } \\
\text { shade/shelter, } \\
\text { extreme climate }\end{array}$ & $\begin{array}{l}\text { Inappropriate } \\
\text { housing, stocking } \\
\text { density, delay in } \\
\text { shearing, extreme } \\
\text { climate }\end{array}$ & $\begin{array}{l}\text { Inappropriate } \\
\text { housing, stocking } \\
\text { density, delay in } \\
\text { shearing, lack of } \\
\text { shade/shelter }\end{array}$ & $\begin{array}{l}\text { Lack of } \\
\text { shade/shelter, } \\
\text { extreme climate, } \\
\text { winter shearing }\end{array}$ \\
\hline Mastitis & $\begin{array}{l}\text { Poor udder } \\
\text { hygiene, teat } \\
\text { lesions, } \\
\text { inappropriate } \\
\text { drying-off, } \\
\text { inappropriate } \\
\text { milking, udder } \\
\text { conformation, } \\
\text { maintenance of } \\
\text { milking system }\end{array}$ & $\begin{array}{l}\text { Poor udder } \\
\text { hygiene, teat } \\
\text { lesions, } \\
\text { inappropriate } \\
\text { drying-off, } \\
\text { inappropriate } \\
\text { milking, udder } \\
\text { conformation, } \\
\text { maintenance of } \\
\text { milking system }\end{array}$ & $\begin{array}{l}\text { Poor udder } \\
\text { hygiene, teat } \\
\text { lesions, } \\
\text { inappropriate } \\
\text { drying-off, } \\
\text { inappropriate } \\
\text { milking, udder } \\
\text { conformation, } \\
\text { maintenance of } \\
\text { milking system }\end{array}$ & $\begin{array}{l}\text { Poor udder } \\
\text { hygiene, teat } \\
\text { lesions, } \\
\text { inappropriate } \\
\text { drying-off }\end{array}$ \\
\hline Lameness & $\begin{array}{l}\text { Pasture conditions } \\
\text { Poor biosecurity } \\
\text { Improper hoof } \\
\text { care }\end{array}$ & $\begin{array}{l}\text { Improper hoof } \\
\text { care, } \\
\text { inappropriate } \\
\text { nutrition, poor } \\
\text { flooring }\end{array}$ & $\begin{array}{l}\text { Improper hoof } \\
\text { care, } \\
\text { inappropriate } \\
\text { nutrition, poor } \\
\text { biosecurity }\end{array}$ & $\begin{array}{l}\text { Soil conditions } \\
\text { (wet), improper } \\
\text { hoof care, } \\
\text { inappropriate } \\
\text { nutrition", poor } \\
\text { biosecurity }^{* *}\end{array}$ \\
\hline
\end{tabular}

